\title{
Study on Sea Trial Analysis of Wave Piercing High Speed Planing Boat
}

\author{
Uh-Cheul Jeong ${ }^{*}$, Chang-Woo Lee ${ }^{* *}$ and Sang-Chun Han ${ }^{* * *}$ \\ *Department of Naval Architecture and Ocean Engineering, Inha Technical College, Incheon, Korea \\ ${ }^{* *}$ Korea Marin Equipment Research Institute, Mokpo, Korea \\ Daewon Marine Technology Co. Ltd., Busan, Korea \\ 파랑관통형 고속 활주선 실선 성능 분석에 관한 연구 \\ 정우철 ${ }^{*}$ 이창우 ${ }^{* *}$ 한상천 \\ "인하공업전문대학 조선해양과 \\ **(재)한국조선해양기자재연구원 \\ (주)대원마린텍
}

KEY WORDS: Wave piercing planing hull 파랑관통형 활주선, Sea trial 해상시운전, Speed performance 속도성능, Vertical acceleration 수직가속도, Turning circle 선회반경

\begin{abstract}
This study investigated the sea trial performance of a wave piercing high speed planing hull (WPH). The bow shape of the boat is sharp, and it has no chine or spray strip like a normal planing boat. The skeg is attached to the bottom of the boat in the longitudinal direction from the bow to the stern. The speed performance was analyzed as the speed dropped in a wave, and the seakeeping performance was compared with that of a planing boat with a similar velocity coefficient by measuring the vertical acceleration of the bow in the wave. The turning circle was compared with Lewandowski's estimation for a planing boat. As a result of this study, it was confirmed that the velocity drop of the developed WPH was not large in a wave, and the vertical acceleration was greatly reduced compared with that of a normal planing boat. The turning circle was somewhat larger than the estimated results for a planing boat, but the overall tendency was the same.
\end{abstract}

\section{1. 서 론}

최근 국내에서 고속선에 대한 관심이 증가하면서 다양한 선 형에 대한 기술개발이 활발히 이루어지고 있다. 대부분의 고속 선은 길이 $10 \mathrm{~m}$ 내외의 단동형 활주선으로 레저활동 뿐 아니라 군사용 등 특수목적으로 사용되고 있다.

국내에서 진행된 주요 연구로, Yoon et al.(2007)은 고속 RIB (Rigid Inflatable Boat)의 조종성능을 예측할 수 있는 간략 모델 을 제시하였고, Jeong et al.(2008)은 소형 고속활주선을 통계적 으로 분석하여 초기선형 개발단계에서 활용할 수 있는 주요제 원 추정식을 제시하였다. Kwon et al.(2012)은 고속 활주선의 종 방향 자세 안정성을 향상시키기 위한 부가물을 개발하였고, Jeong et al.(2012)은 알루미늄합금 고속선의 성능을 동급의 FRP(Fiber reinforced plastic) 보트와 비교 연구를 수행한 바 있
다. Kim et al.(2014)은 3 톤급 소형 활주선의 선형변화에 따른 저 항성능과 내항성능을 수조시험을 통하여 비교연구를 수행하였 다. 이러한 연구들은 전통적인 활주선을 대상으로 하고 있어 내 파성능이 불리하고, 선저에 작용하는 선저충격(Slamming)이 크 게 발생한다는 문제를 가지고 있다.

미국, 유럽 등 해외 선진국들은 오랫동안 성능 향상을 위하여 많은 연구개발을 수행하여 왔으며, 특히 고속과 안전에 대한 기 술개발에 많은 노력을 기울이고 있다. 그 중 VSV(Very slender vessel)(Thompson, 1997)와 TH(Transonic hull)(Calderon and Hedd, 2011)는 기존 활주선과는 달리 선수부 형상이 도끼날처럼 뾰족 한 형상을 가지고 있어 파랑 중 내파성능이 기존의 활주선보다 우수하다고 알려져 있다. 특히 VSV는 활주선과 유사한 챠인 (Chine)과 Spray strip을 가지고 있으며, $\mathrm{TH}$ 는 선수부는 VSV와 유사한 뾰족한 형상이나, 선미부에서의 선저경사각이 극단적으

Received 13 July 2017, revised 24 October 2017, accepted 24 October 2017

Corresponding author Uh-Cheul Jeong: +82-32-870-2176, ucjeong@inhatc.ac.kr

It is noted that this paper revised edition based on proceedings of KSOE 2017 in Busan.

(C) 2017, The Korean Society of Ocean Engineers

This is an open access article distributed under the terms of the creative commons attribution non-commercial license (http://creativecommons.org/licenses/by-nc/3.0) which permits unrestricted non-commercial use, distribution, and reproduction in any medium, provided the original work is properly cited. 
로 작은 상자모양과 유사한 형상이고, 챠인이 없는 배수량형 선 형이다. 이러한 형태의 선형은 특수 목적의 쌍동선이나 삼동선 형태로 설계되어 고속선에 활용되기도 한다.

최근 국내에서도 이와 유사한 선형에 대한 연구가 수행되고 있다(Seo et al., 2016; Jeong et al., 2016). Seo et al.(2016)이 대상 으로 한 선형은 VSV에 가까운 선형이다. 반면 Jeong et al.(2016) 이 개발한 선형은 선수부 선저경사각이 큰 활주선이나, 기존의 $\mathrm{VSV}$ 와 달리 챠인이나 Spray strip이 없고, $\mathrm{TH}$ 와는 선미부 형상 이 다른 활주선 형상으로 배수량이 어느 정도 확보되어 있다. 또한 길이방향으로 선미단에서 선수까지 선저에 스케그(Skeg) 가 부착되어 있다.

이러한 대부분의 연구들은 모형시험을 통한 개념 정립 단계 로, 실선에 대한 해상 성능 검증에 대한 연구는 수행되지 않았 다. 본 연구에서는 Jeong et al.(2016)이 레저보트로 개발한 파랑 관통형 고속활주선의 실선성능을 유사한 속도계수를 갖는 활주 선의 실선성능과 비교하였다.

\section{2. 대상선박 특성 및 성능평가 조건}

\section{1 대상선박 특성}

본 연구의 대상선박은 Jeong et al.(2016)이 개발한 파랑관통형 고속활주선(Wave Piercing High Speed Planing Hull; WPH)으로 선 수부 형상은 선저경사각이 매우 큰 도끼날 형상을 가지고 있다. 전장은 $8 \mathrm{~m}$ 이고 최대선속은 250 마력 선외기 기준 35 노트이며, 배수 량은 약 2ton이다(Fig. 1(a)). 비교 대상선은 전장 $6 \mathrm{~m}$, 배수량 1.3 톤, 150 마력 선외기(Outboard Engine) 기준 최대 32노트의 일반적인 활 주선이다(Fig. 1(b)). 두 척의 최대속도에서의 배수량 기준 체적푸 루우드수(식 (1))는 각각 5.1, 5.0으로 유사한 속도계수를 가지고 있다. 여기에서 $\nabla$ 는 배수용적이고, $V$ 는 선속이다. 두 선박의 주요 제원과 실선 형상을 Fig. 1과 Table 1에 각각 나타내었다.

$$
F_{\nabla}=\frac{V}{\sqrt{g \nabla^{1 / 3}}}
$$

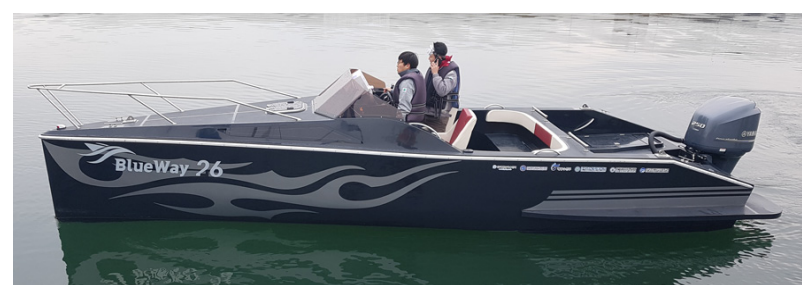

(a) WPH

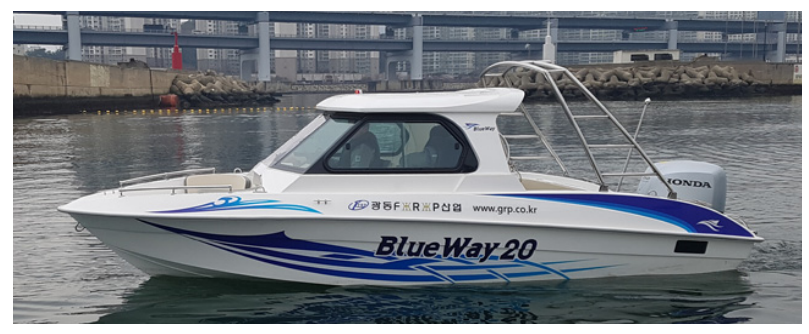

(b) Planing boat

Fig. 1 Actual ship of WPH and planing boat
Table 1 Principal dimensions of test boats

\begin{tabular}{cccc}
\hline \hline Items & Unit & WPH & Planing boat \\
\hline LOA & $\mathrm{m}$ & 8.0 & 6.0 \\
B(lwl) & $\mathrm{m}$ & 2.2 & 2.1 \\
Draft & $\mathrm{m}$ & 0.3 & 0.4 \\
Disp. & ton & 2.0 & 1.3 \\
\hline
\end{tabular}

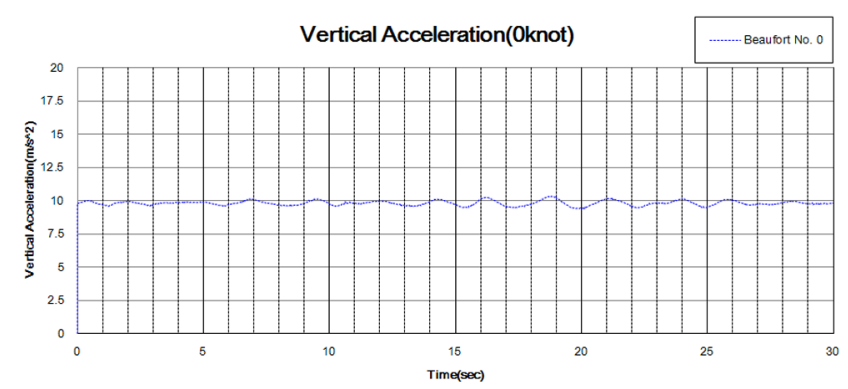

Fig. 2 Vertical acceleration for WPH (V=0knot, BN 0)

\section{2 성능평가 조건}

본 개발선에 대한 실해상 성능을 평가하기 위하여 파랑이 없 는 해상조건 및 파랑이 있는 조건에서 엔진 회전수 변화에 따 른 선속을 계측하여 개발선의 파랑 중 속도변화를 분석하였고, 동일한 해상조건에서 선수부 수직가속도를 계측하여 비교대상 활주선의 수직가속도와 비교하였다. 파랑조건은 풍력등급 인 Beaufort scale No.0(BN 0)와 No.4(BN 4) 기준이다. 또한 정수 중 선회반경을 계측하여 Lewandowski(2004)의 활주선에 대한 추정 식과 비교하였다.

속도성능과 선회반경은 선내에 부착된 GPS기의 정보를 이용 하였고, 가속도 계측을 위한 센서(가속도계)의 최대 계측범위는 $\pm 8 \mathrm{G}$, 계측민감도는 $0.00244 \mathrm{G}$ 이다. 가속도계는 두 선박 모두 선 미단에서 길이 방향으로 약 $85 \%$ 위치에 부착하였다.

Fig. 2는 선수부 상하가속도 계측을 위한 가속도 계측기의 검 증 결과이다. 파랑이 없는 해상조건( $\mathrm{BN} 0)$, 정지상태에서 본 개 발선에 대한 계측결과, $1 \mathrm{G}\left(9.8 \mathrm{~m} / \mathrm{sec}^{2}\right)$ 를 중심으로 작은 진폭으로 진동하고 있으며, 평균값은 $9.833 \mathrm{~m} / \mathrm{sec}^{2}$ 이다. 본 계측기의 신뢰 도를 확인할 수 있다.

\section{3. 실선 성능 분석}

파도가 거의 없는 $\mathrm{BN} 0$ 와 약간 거친 해상상태인 $\mathrm{BN} 4$ 에서 엔진(250마력 선외기) 회전수 변화에 따른 본 개발선의 선속을 계측하여 Fig. 3에 나타내었다. 속도는 선내에 부착된 GPS기에 서 제공한 값이다. 바람과 조류의 영향을 고려하여 반복 운항을 한 후의 평균값을 산출하였다.

일반적인 활주선의 경우, 파랑 중 내파성능이 불량하고 속도 저하가 나타난다(Kihara and Ishii, 1986; Niwa, 2002). 본 개발선 과 유사한 형상의 VSV의 경우에서도 파랑 중 속도저하가 나타 나고 있으나(Seo et al., 2016), 본 개발선의 경우에는 전반적으로 속도저하가 거의 없다. 그 이유는 본 개발선은 일반적인 활주선 및 VSV와는 달리 항주트림이 크지 않고(Jeong et al., 2016), 고 


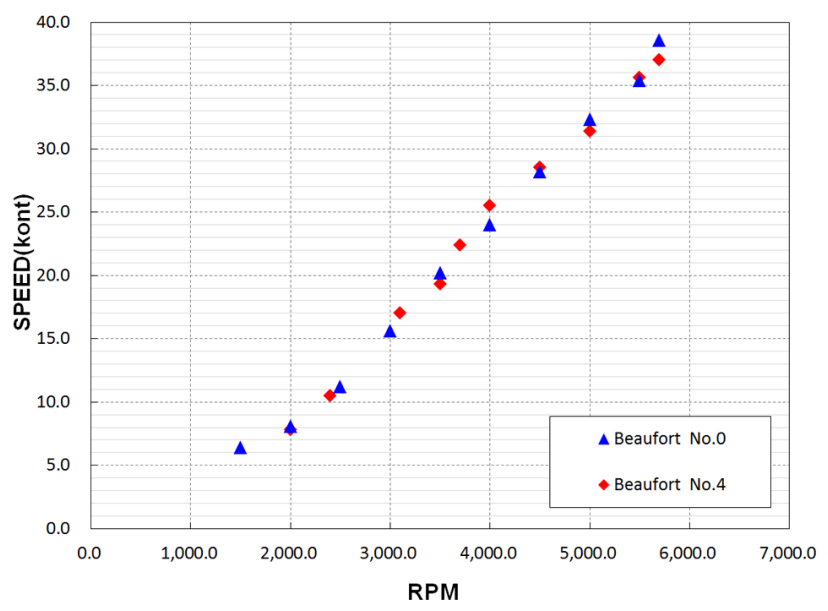

Fig. 3 Comparison of speed for WPH at BN 0 \& BN 4

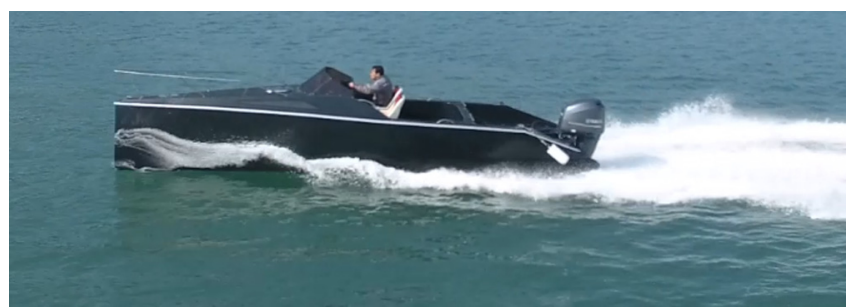

Fig. 4 Sea trial for measurement of speed, WPH (V=35knots)

속영역에서도 수면을 관통하면서 항주하는 관계로 파랑 속에서 도 안정적으로 운항하기 때문이다(Fig. 4). 4000RPM 영역에서는 파랑 중에서 약 1.5 노트 정도 우수한 것으로 나타났으나, 이는 계측 오차라고 판단된다. 본 개발선의 파랑 중 속도성능을 보다 정확히 파악하기 위해서는 다양한 해상조건에서의 속도성능 분 석이 추가적으로 필요하다.

본 개발선의 모형시험 결과에 따르면 선외기 추진효율 $(\eta)$ 을 0.60 으로 가정하고, $15 \%$ Sea margin을 고려하였을 경우 정수 중 최대선속 35노트를 위하여 230마력 선외기가 필요한 것으로 추 정되었고(Jeong et al., 2016), 시운전 결과 본 개발선에 장착한 250 마력 선외기 최대RPM(5800)의 약 $95 \%$ 인 $5500 \mathrm{RPM}$ 이 필요 한 것으로 나타났다. 선외기 RPM과 엔진출력과의 관계는 선외 기 제조사의 대외비인 관계로 공개된 정보는 없으나, 선형적인 관계라고 가정하면 본 시운전 결과는 모형시험 결과와 유사하 다고 판단된다.

Fig. 5는 선속 20 노트, 해상조건 $\mathrm{BN} \mathrm{4}$ 에서 본 개발선과 비교 대상 활주선의 선수부 상하가속도 계측결과이다. 계측시간은 목표선속에 도달했을 때를 기점으로 20 초간 실시하였으며, 계 측결과를 실효값인 RMS(Root Mean Square)로 변환하여 비교하 였다. 활주선의 경우, 동일 조건에서 위 방향으로의 가속도가 전반적으로 크게 나타난다. 그 이유는 수면에 부딪히는 충격으 로 위 방향으로의 운동이 상대적으로 크기 때문이다. 극단적인 피크 값을 제외하면 활주선의 경우 가속도 범위가 약 $0 \sim 20 \mathrm{~m} / \mathrm{s}^{2}$ $( \pm 2 \mathrm{G})$ 범위인 반면, 본 개발선의 경우 약 $5 \sim 15 \mathrm{~m} / \mathrm{s}^{2}( \pm 1.5 \mathrm{G})$ 범위 이다. 본 개발선의 가속도가 활주선에 비하여 약 $25 \%$ 정도 감 소하는 경향을 보이고, 시간변화에 따른 가속도 변화가 상대적 으로 작게 나타난다.

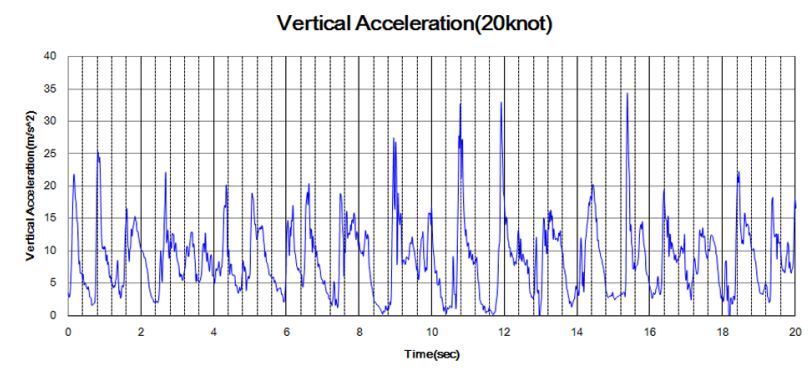

(a) planing hull

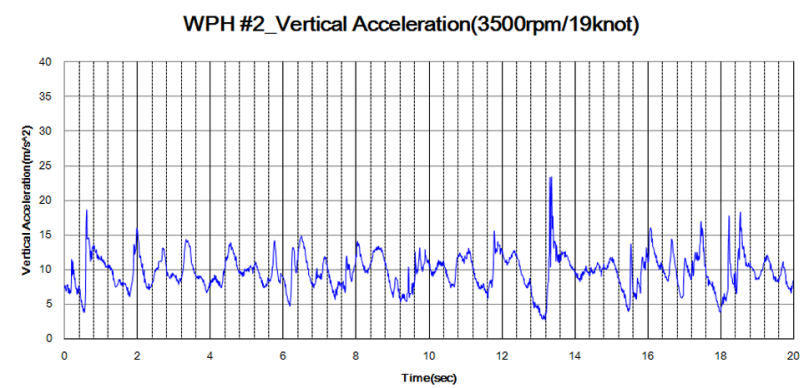

(b) WPH

Fig. 5 Comparison of vertical acceleration ( $V=20 \mathrm{knot}, \mathrm{BN}$ 4)

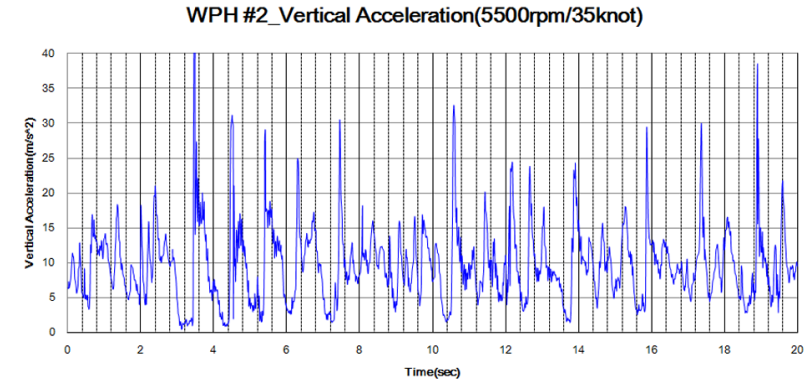

Fig. 6 Vertical acceleration, WPH (V=35knot, BN 4)

Fig. 6은 본 개발선의 파랑 중(BN 4) 35 노트에서 선수부 가속 도 계측결과이다. 활주선의 경우, 동일한 파랑 조건에서 안전한 운항이 어려워 고속에서는 계측이 불가능하였다. 본 개발선의 20노트 경우(Fig. 5(b))보다 가속도가 증가하고, 활주선의 20노트 경우(Fig. 5(a))와 유사한 범위이다. 즉, 동일 조건에서 본 개발선 의 선수부 상하가속도는 활주선의 상하가속도보다 크게 감소하 여 본 개발선의 내파성능이 활주선에 비하여 우수하다도 판단 된다. 그 이유는 본 개발선의 선수부 선저경사각이 큰 관계로 선저에 작용하는 파랑 하중이 감소하기 때문이고, 이는 Kihara and Ishii(1986), Kim et al.(2014) 등이 언급한 바와 같이 선수부 선저 경사각이 클수록 선수부 수직가속도가 감소하여 내항성능 이 향상된다는 연구와 동일한 경향이다.

선저경사각과 수직가속도 변화량에 대한 상관관계는 보다 다 양한 체계적인 연구가 필요한 부분이다.

본 개발선의 정수중 선회반경을 계측하여 Lewandowski의 추 정식(2004)과 비교하였다. 본 선회반경 추정식(식 (2))은 프로펠 러와 타를 장착한 고속 활주선에 대한 추정식으로 선외기를 부 착한 본 개발선과는 다소 차이가 있으나, 본 개발선과 유사한 선형에 대하여 본 추정식의 활용 가능성을 확인하고자 하였다. 


$$
D_{s} / L \approx\left[1.7+0.0222 F_{\nabla}\left(\frac{L}{\nabla^{1 / 3}}\right)\right]\left(\frac{30}{\delta}\right)
$$

여기에서 $D_{s}, L, \nabla, F_{\nabla}, \delta$ 는 각각 선외지름, 배의 길이, 배수용 적, 체적푸루우드수, 타각(deg)을 나타낸다. 상기 식 (2)의 유효 범위는 아래와 같다.

$$
\begin{aligned}
& 0.3 \leq F_{\nabla} \leq 4.0 \\
& 4.5 \leq \frac{L}{\nabla^{1 / 3}} \leq 7
\end{aligned}
$$

본 개발선의 $L / \nabla^{1 / 3}$ 은 약 6.2 이고, 추진기 RPM에 대한 선속 별 체적푸루우드수 $\left(F_{\nabla}\right)$ 는 Table 2와 같다. 상기 식 (3)의 유효범 위를 고려하여 $8,16,24$ 노트 세 속도에서 실선 계측 선회반경 과 추정결과와 비교하였다.

Table 2 Froude number based on displacement volume

\begin{tabular}{ccc}
\hline \hline RPM & Speed [knot] & $F_{\nabla}$ \\
\hline 2000 & 8 & 1.18 \\
3000 & 16 & 2.35 \\
4000 & 24 & 3.54 \\
\hline
\end{tabular}

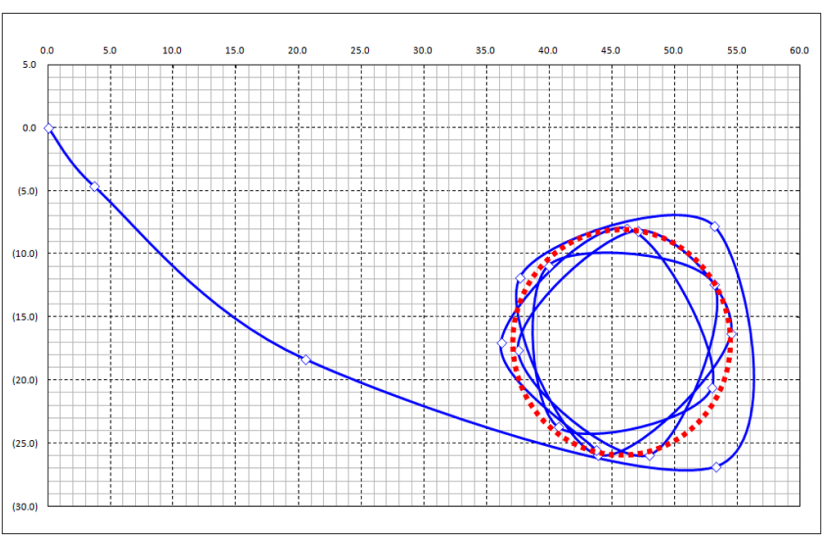

(a) Left

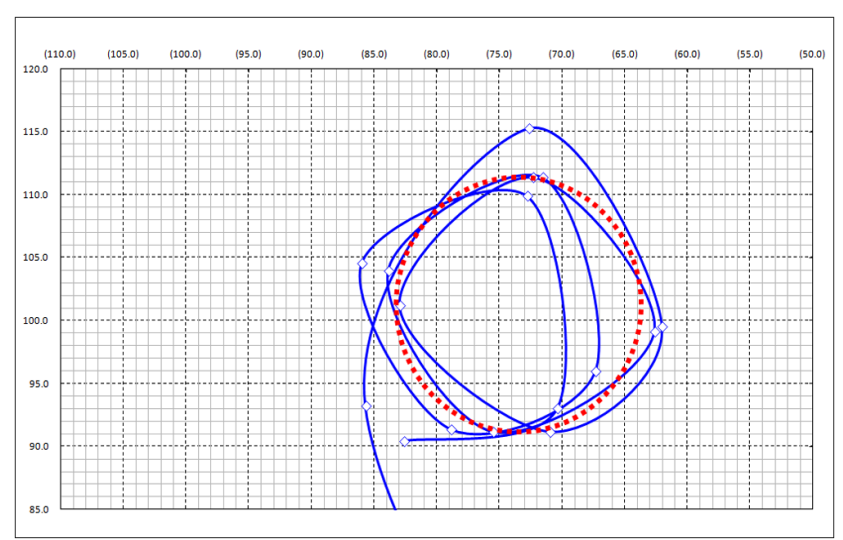

(b) Right

Fig. 7 Sea trial for measurement of turning circle, WPH (V=16knots, $\mathrm{BN}$ 0)
Table 3 Comparison of turning circle

\begin{tabular}{ccc}
\hline \hline \multirow{2}{*}{ Speed $[\mathrm{knot}]$} & \multicolumn{2}{c}{ Turning radius [m] } \\
\cline { 2 - 3 } & Sea trial & Estimation \\
\hline 8 & 8.85 & 6.4 \\
16 & 9.10 & 7.0 \\
24 & 11.25 & 7.6 \\
\hline
\end{tabular}

Fig. 7은 본 개발선의 정수중 16 노트에서 선외기 좌우 최대각 35 도에 대한 선외항적이다. 도시된 값은 선내에 부착된 $\mathrm{GPS}$ 의 경위도 좌표값으로 선회직경 값이고, 평균 직경을 점선으로 도 시하였다. 좌우 각각 약 $8.75 \mathrm{~m}, 9.5 \mathrm{~m}$ 정도의 선회반경으로 평균 약 $9.1 \mathrm{~m}$ 정도이다. 좌우 비대칭 원인은 본 개발선은 소형선박으 로 바람과 조류의 영향이 민감하게 작용할 뿐 아니라 프로펠러 추진으로 인한 불평형성 때문이라고 판단된다.

앞에서 언급한 세 속도에 대한 시운전 계측 선외반경과 식 (2)에 의한 선외반경 추정결과를 Table 3에 나타내었다. 좌우 최대 35도 에 대한 결과로, 좌우 선회에 대한 평균값이다. 식 (2)를 이용한 추정 시, 배수용적은 정적배수용적(Hydrostatic displacement volume) 을 사용하였다.

속도가 증가할수록 선외반경이 증가하는 전반적인 경향은 동 일하나, 시운전 결과가 추정치에 비하여 크게 나타나고, 속도가 증가할수록 그 차이는 커지고 있다. 그 이유는 앞에서 언급한 바와 같이 본 추정식은 일반적인 활주선에 대한 것으로 본 개 발선과는 선형 차이에 따른 운항 특성이 서로 다르기 때문이다. 일반적인 활주선은 속도가 증가할수록 선체 대부분이 부상하여 운항하는 반면, 본 개발선은 선체 부상량이 작고 수면을 관통하 여 항주하기 때문에 속도가 증가할수록 그 차이는 증가한다고 판단된다. 향후 본 개발선과 같은 선형에 적합한 추정식 개발이 필요한 부분이다.

\section{4. 결 론}

본 논문에서는 파랑관통형 고속 활주선의 실선 성능에 대하 여 언급하였다. 본 연구 대상선은 선수부 형상이 도끼날 형상으 로 뾰족하고, 기존 활주선이 가지고 있는 챠인과 Spray strip이 부착되어 있지 않다. 실선 성능은 유사한 속도계수를 갖는 활주 선의 실선 성능과 비교하였고, 선외반경은 Lewandowski의 활주 선에 대한 추정식과 비교하였다. 본 연구결과, 다음과 같은 결 론을 도출하였다.

(1) 본 개발선의 정수중 속도성능은 250 마력 선외기 최대 RPM 기준 38 노트이고, 35 노트를 위하여 $95 \% \mathrm{RPM}$ 이 필요하여 모형시 험 결과(Jeong et al.,(2016))와 유사하다는 것을 확인하였다

(2) 본 개발선의 파랑 중 속도변화는 거의 없다. 그 이유는 본 개발선은 일반적인 활주선 및 VSV와는 달리 항주트림이 크지 않고, 고속영역에서도 수면을 관통하면서 항주하는 관계로 파 랑 속에서도 안정적으로 운항하기 때문이다. 그러나 파랑 중 속 도성능을 보다 정확히 파악하기 위해서는 다양한 해상조건에서 의 속도성능 분석이 추가적으로 필요하다.

(3) 본 개발선의 선수부 상하가속도는 유사한 규모의 활주선 
에 비하여 크게 감소한다. 선속 20 노트, BN4 기준 약 $25 \%$ 정도 감소하였다. 그 이유는 본 개발선의 선수부 선저경사각이 크기 때문에 선수부 선저에 작용하는 파랑 충격이 상대적으로 작기 때문이다.

(4) 선외반경 시운전 결과는 활주선에 대한 추정결과보다 다 소 크게 나타났다. 그 이유는 기존 활주선과 본 개발선의 운항 특성 차이 때문이라고 판단된다. 향후 본 개발선과 같은 선형에 적합한 추정식 개발이 필요하다.

$$
\text { 후 기 }
$$

본 연구는 2014년 해양수산부 재원으로 해양수산기술진흥원 의 지원을 받아 수행한 미래해양산업기술개발사업(과제명 : 글 로벌 해양레저시장 진출을 위한 파랑 안정형 고속 레저보트 개 발(20140112))의 결과입니다.

\section{References}

Calderon, A., Hedd, L., 2011. Theoretical and Experimental Investigation on Resistance of Transonic Hulls. Proceeding of 9th HSMV, Naples, 25-27.

Jeong, U.C., Park, J.W., Kim, K.S., 2008. Hull Form Development of 32-ft Class Leisure Boat by Statistical Analysis of Actual Ship. Journal of Ocean Engineering and Technology, 22(3), 58-63.

Jeong, U.C., Kim, D.J., Choi, H.S., 2012. Study on Hull Form Development and Resistance Performance of High Speed Aluminum Leisure Boat. Journal of Ocean Engineering and Technology, 26(6), 14-18.

Jeong, U.C., Lee, D.K., Jung, K.S., 2016. Study on Hull Form Development of Wave-Piercing-Type High-Speed Planing Boat.
Journal of Ocean Engineering and Technology, 30(2), 69-74. Kihara, K., Ishii, T., 1986. A New Method of Initial Design for High Speed Craft(2). Transition of West Japan Society of Naval Architecture, Vol 72, pp 293-300.

Kim, D.J., Kim, S.Y., Kim, S.H., Seo, J.H., Rhee, S.H., 2014. Effects of Hull Form Variations on Resistance and Seakeeping Performance of Planing Hulls with and without Incoming Regular Waves. Journal of the Society of Naval Architects of Korea, 51(5), 369-379.

Kwon, S.Y., Jeong, U.C., Hong, K.S., Lee, H.J., Na, H.J., 2012. Study on Development of Control Fin of Longitudinal Position for High Speed Leisure Boat. Proceeding of KAOSTS, Daegu Korea, 1189-1192.

Lewandowski, E.M., 2004. The Dynamics of Marine Craft (Manuevering and Seakeeping). World Scientific Publishing Company, Singapore.

Niwa, S., 2002. Engineering of High Speed Boat(Resistance and Propulsion). A Foundation of Ship and Ocean(in Japanese), Tokyo.

Seo, J., Choi, H.K., Jeong, U.C., Lee, D.K., Rhee, S.H., Jung, C.M., Yoo, J., 2016. Model Tests on Resistance and Seakeeping Performance of Wave-Piercing High-Speed Vessel with Spray Rails. International Journal of Naval Architecture and Ocean Engineering, 8, 442-455.

Thompson, A., 1997. U.S. Patent No. 6116180. United States Patent and Trademark Office.

Yoon, H.K., Yeo, D.J., Fang, T.H., Lee, C.M., 2007. A Simplified Horizontal Maneuvering Model of a RIB-Type Target Ship. Journal of the Society of Naval Architects of Korea, 44(6), $572-578$. 